\title{
Model Stability Test of Money Demand by Monthly Time Series Using CUSUM and MOSUM Tests: Evidence from Turkey
}

\author{
Emrah Talaş ${ }^{1}$, Fatih Kaplan² \& Ali Kemal Çelik ${ }^{3}$ \\ ${ }^{1}$ Department of Econometrics, Atatürk University, Erzurum, Turkey \\ 2 Department of Economics, Bingöl University, Bingöl, Turkey \\ ${ }^{3}$ Department of Business Administration, Atatürk University, Erzurum, Turkey \\ Correspondence: Ali Kemal Çelik, Department of Business Administration, Atatürk University, Erzurum 25240, \\ Turkey. Tel: 90-442-231-2099. E-mail: akemal.celik@atauni.edu.tr
}

Received: May 9, 2013

doi:10.5430/rwe.v4n2p36
Accepted: June 7, 2013

Online Published: June 30, 2013

This paper is an extended and revised version of the conference paper presented at " 8 " International Syposium of Statistics", on 11-13 October 2012, Eskisehir, Turkey.

\begin{abstract}
The effects of policies are represented by the parameters of the concerning estimated model. As Lucas critique suggests unless the parameters change with respect to policies, the existing policies will be valid in the long-run. However, policy change can be observed at an unknown point and slowly in particular time period, then these policies will not be associated with structural change. In this study, model stability of money demand constituted by monthly time series concerning the periods of 2001:5-2011:3 in Turkey was tested by recursive CUSUM and MOSUM tests. The results of CUSUM and MOSUM tests demonstrated a single-continuous break and two discrete breaks. In this period, slow structural breaks in the model were thought to be caused by the inflation targeting policies, restricted money supply and short-term interest policies of the government.
\end{abstract}

Keywords: money demand, stability, CUSUM test, MOSUM test, R computer package program for statistics

\section{Introduction}

Suggestions of economic policy stand for the accurate estimation of the relationships among variables. Parameters of the estimated model indicate the effects of policies. If the parameters do not change with respect to policies, it may be suggested that the existing policies are valid in the long-term. This situation is known as Lucas critique in the literature. If the policy change is recognized at an unknown point and slowly in particular time period (as shown in Lucas critique), it may be inferred that the policies are not considered with structural change (Greene, 2002). This circumstance may damage the succes of explanatory power of the model and may cause the invalidity of the results, so the stability of model should be tested by convenient methods.

There were various studies regarding model stability in the literature. These studies stand for Lucas critique (1981), which argues that "the economic policies must change whenever the parameters of the model change". The common suggestion of the studies refers to the neccessity of model stability against policy changes in order to use the model as an economy policy. Model stability can be tested by package programs with developing technology. In these programs, CUSUM and CUSUMQ packages are generally used.

This study considers specific model stability tests that can be used when the policy change is slowly recognized in a time period at an unknown point. There are certain weaknesses of frequently used CUSUM and CUSUMQ model consistency tests statistically (Andrew, 1993; Yashchin, 1993; Turner, 2010). MOSUM test, which was constructed based on the cumulative sums of the recursive resudials as CUSUM test, enables more robust estimation than COSUM test and therefore gives more information about the model (Chu et al., 1995, Zeileis et al., 2002). For these reasons, the results of two tests were involved in the study.

The paper is organized as follows. Section 2 involves the studies in the literature associated with model stability tests, Section 3 consists of econometric methodology and model form about time series analysis, furthermore after the 
variables used in the study are introduced, the results of unit root, cointegration, CUSUM and MOSUM tests being obtained by using Eviews- 6 and R-2.14.2 package programs are interpreted respectively. Section 4 concludes the study.

\section{Literature Review}

One of the most substantial tasks in econometrics and statistics is to investigate techniques enabling the researchers to estimate the unknown parameters of a specific model, while estimation procedures on the basis of the minimization or minimization of some kind of criterion functions were successfully used for several types of models (Harris \& Mátyás, 1999). Model stability is an important requirement for convenient econometric estimation and interpretation (Hansen, 1992). Chow (1960) test is the most common test for examining the parameters of the model, which stands for the assumption of a single break, is occurred in a particular point of time. Even if, Quandt (1960) test was not so popular as Chow test when invented, it is an alternative test to examine the model stability which prior knowledge is not needed, namely the break time is unknown (Khedhiri, 2006).

Various studies concerning structural break tests were accomplished, following the studies of Chow and Quandt. In these studies, structural break tests were developed by using the models, methods and techniques such as maximum likelihood, generalized method of moments (GMM) or ordinary least squares (OLS) techniques (Zeileis, 2005). Maximum likelihood is adopted as the most widely used estimation technique; however it requires the complete specification of the model and its probability distribution. GMM differs from maximum likelihood technique where this technique does not require full information (Harris \& Mátyás, 1999). Nyblom (1989) proved alternative Lagrange Multiplier (LM) scores to estimate the random walk of paremeters. This test was developed by Hansen (1992) for linear regression models. Asymptotic models for estimating model stability by the agency of GMM were developed by Andrews (1993, sup $F$ test) and Andrews and Ploberger (1994, average and exponential $F$ tests). Hall and Sen (1999) proposed a methodology for testing structural stability in models estimated via GMM and their results exhibited structural instability for all considered models.

Hjort and Koning (2002) suggested a generalized classification of structural break tests based on maximum likelihood statistics. Andrews (2003) considered tests for structural instability of short duration and he generalized the $\mathrm{F}$ test to cover regression models with much more general error processes. In addition, he extended the $F$ test to nonlinear models estimated by GMM and maximum likelihood. Jondeau et al. (2004) examined the estimates of the Federal Reserve reaction function using several GMM estimators and a maximum likelihood estimator and they found the disperancy is more plausibly rationalized by serial correlation of the policy shock which causes misspecification of GMM estimators through lack of instrument exogeneity. Maheu and Gordon (2004) presented a general methodology for forecasting in the presence of model instability and discussed the importance of using priors that reflect plausible forecast. Gagliardini et al. (2005) proposed a class of new robust GMM tests for endogenous structural breaks and they found that the performance of classical asymptotic GMM tests could be unstable under slight departures from some given reference distribution.

Clark and McCracken (2005) compared the power of tests in the presence of structural breaks based on empirical evidence on the effects of structural breaks on tests for equal forecast accuracy and encompassing and they concluded that structural breaks under the alternative might achieve to explain why researchers often find evidence of in-sample, but not out-of-sample, predictive content. Zeileis and Hornik (2007) suggested a general class of fluctuation tests for parameter instability in an M-estimation framework and the usefulness of the test procedures is illustrated using various specific application areas. Chou (2007) studied the finite-sample properties of the LM unit root tests when level shifts were allowed under the null hypothesis using a bootstrap approach and bootstrapped critical values supported the invariance property of the LM tests. Li and Müller (2009) considered time series GMM models where a subset of the parameters were time varying and they showed that for many forms of instability and a large class of GMM models, usual GMM inference on the subset of stable parameters was asymptotically unaffected by the partial instability.

Brown et al. (1975) introduced recursive CUSUM test to establish the structural breaks on linear models which is estimated using least squares method. Lee et al. (1997) examined the effect of a structural break on stationary tests and their results clarified the nature of the effects of a structural break on inference regarding integrated time series. Bahmani-Oskooee and Bohl (2000) studied the stability of the German M3 money demand function with CUSUM and CUSUMQ applications in the context of error-correction modeling and cointegration and some instability in M3 money demand function was observed. Luger (2001) proposed a modified CUSUM test for orthogonal structural changes and he suggested that this modified test provides to detect orthogonal structural changes. Similarly, Presno and López (2003) estimated response surfaces for a modified stationary test that allow the approximation of critical 
values for different break locations and sample sizes and they found that the finite sample distribution of the test is affected by the relative position of the break in both the sample and the sample size. Zeileis et al. (2008) suggested an algorithm for model-based recursive partitioning to test for parameter instability over a set of partitioning variables which enabled a parametric model that could be effectively visualized. King and Ramlogan-Dobson (2011) investigated the role of structural breaks on nonlinear time-series convergence by using the data on real GDP per capita covering the period 1950-2004 for 15 OECD countries and greater evidence of convergence with tests that permit structural break was consistent with the view that European economies experienced multiple growth phases over the postwar period.

CUSUM and MOSUM tests which stand for OLS method (Ploberger \& Krämer, 1992; Chu et al., 1995) are very popular as they provide easier calculation. However, CUSUM and CUSUMQ tests which can be obtained by similar methods have some weaknesses. For instance, if there is serial correlation problem between the data of the model, the explanatory power of model stability of CUSUM test is insufficient (Andrew, 1993; Yashchin, 1993). Therefore, if the model, allowing structural break, involves a constant term, CUSUM test produces more robust results than CUSUMQ test (Turner, 2010). MOSUM test enables more robust estimations than CUSUM and CUSUMQ tests for establishing model stability and gives more knowledge about the model (Zeileis et al., 2002). For these reasons, in this study both recursive CUSUM and CUSUMQ tests were used.

\section{Data Set and Model}

In this study, model stability of money demand constituted by monthly time series concerning the periods 2001:5-2011:3, was investigated. The inflation ratio (INF), short- term real interest ratio (I), money supply (M2), real exchange rate (RER) and gross domestic product (GDP) data of the study were gathered from the databases of Turkish Statistical Institute and Central Bank of the Republic of Turkey (CBRT). Exchange rate increase denotes the real value appreciation of Turkish Lira (TL). Overnight interest rates of CBRT were used in the study. After averaging monthly overnight borrowing interest rates, monthly real interest rates were computed by the help of the following formula:

$$
\text { real interest }=((1+\text { interest rate }) /(1+\text { inflation rate }))-1 \times 100
$$

Consumer Price Index (CPI) denotes inflation rates in the study. Inflation data concerning the evaluation period on the basis of CPI, was computed by the help of the following formula:

$$
\left(\mathrm{CPI}-\mathrm{CPI}_{-1}\right) /\left(\mathrm{CPI}_{-1}\right) * 100
$$

The data concerning money supply variable was labed as M2 with respect to new money supply definition and was represented in terms of thousand Turkish Liras. Besides, M2 was realized by dividing to CPI.

In the study, the following formula was used in order to denote money demand in accordance with recent representative studies (Akinlo, 2006; Bahmani-Oskooee, 2001; Bahmani-Oskooee \& Chomsisengphet, 2002; Bahmani-Oskooee \& Shin, 2002; Oomes \& Ohnsorge, 2005). According to this model, money demand (M2) was constituted as a function of interest (I), income (GDP) and inflation (INF).

$$
\mathrm{M}_{2}=\mathrm{c}+\alpha \mathrm{I}_{\mathrm{t}}+\beta \mathrm{GDP}_{\mathrm{t}}+\gamma \mathrm{RER}_{\mathrm{t}}
$$

Although, inflation was also used in various studies concerning money demand model, because of the high correlation between inflation and interest (0.652) in the study, it was not included in this model to avoid multicollinearity error.

\subsection{Unit Root Test}

Because the variables used in the study were time series data, unit root test was primarily applied to the corresponding variables. Variables have to be stationary in time series analysis and if the series are not stationary, they are not able to carry sufficient information about the past (Gujarati, 1999, Enders, 1995). For these reasons, the stationary analyses of the variables were tested by using Phillips-Perron (P-P) unit root test. According to P-P unit root test results in Table 1, M2 and RDK variables were found as stationary on the first difference level and the other variables were stationary on their own levels.

\subsection{Co-integration Test}

Co-integration test is intended to establish the long-term stationaries of linear combinations for nonstationary variables. The existence of cointegration between variables with respect to test results may be suggested as a real long-term relationship, in this situation the variables were able to be used in the model in case of levels. For this purpose, whether cointegration has been observed among the variables were tested by Johansen co-integration test (Johansen \& Juselius, 
1990). Eigenvalues, trace statistics and maximum eigenvalues with critical values at the 0,05 significance level were shown in Table 2.

Co-integration analysis indicates that null hypothesis $\left(\mathrm{H}_{0}\right)$, which advocates there is no cointegration among the variables, was rejected at the 0,05 significant level. This situation suggests that there are long-term relationships between the variables.

Table 1. P-P unit test results

\begin{tabular}{lrrrrr}
\hline \multirow{2}{*}{ Variables } & \multicolumn{2}{c}{ Levels } & \multicolumn{2}{c}{ First Differences } \\
\cline { 2 - 6 } & $\begin{array}{c}\text { With } \\
\text { Constant }\end{array}$ & $\begin{array}{c}\text { With Constant/With } \\
\text { Trend }\end{array}$ & $\begin{array}{c}\text { With } \\
\text { Constant }\end{array}$ & $\begin{array}{c}\text { With Constant/With } \\
\text { Trend }\end{array}$ \\
\hline M2 & 2.28 & -2.77 & -8.60 & -9.10 \\
I & -7.54 & -8.01 & -37.51 & -38.49 \\
GDP & -0.87 & -5.40 & -12.52 & -12.46 \\
RER & -2.40 & -3.48 & -2.15 & -6.71 & -6.84 \\
$*$ & $=\quad \% 1$ & -2.88 & -4.03 & 3.48 & 4.03 \\
$* * \quad=\quad \% 5$ & -2.57 & -3.44 & -2.88 & -3.44 \\
$* * * *=\% 10$ & & -3.14 & -2.57 & -3.14 \\
\hline
\end{tabular}

\subsection{Test of Model Stability}

In some studies concerning money demand model, it was interpreted that the cointegration among variables, is the indicator of model stability. Bahmani-Oskooee \& Chomsisengphet (2002), Bahmani-Oskooee \& Rehman (2005), and Bahmani-Oskooee \& Economidou (2005) have introduced that the co-integration does not imply model stability. Money demand model stability was primarily investigated by cumulative sum of recursive resudials (CUSUM) test. Brown et al. (1975) defined this test with the formula below (Zeileis et al., 2002). According to authors, the cumulative sum of residuals are,

$$
W_{n}(t)=\frac{1}{\widetilde{\sigma} \sqrt{\eta}} \sum_{i=k+1}^{k+\left\lfloor t_{\eta}\right\rfloor} \tilde{u}_{i}, 0 \leq t \leq 1
$$

where $\eta=n-k$ denotes the number of recursive residuals. In addition, according to central limit theorem $W_{n}$ converges to $W$. Structural break was acquired by the use of Rec-CUSUM test and R package program. With respect to test results, a structural break was observed on the model between the time periods of 0.4 and 0.5 . One method of establishing structural breaks using cumulative sum is MOSUM test. This recursive MOSUM test (Zeileis et al., 2002) was defined as follows:

$$
\begin{gathered}
M_{n}(t \mid h)=\frac{1}{\widetilde{\sigma} \sqrt{\eta}} \sum_{i=k+\left\lfloor N_{\eta} t\right\rfloor+1}^{\left.k+\left\lfloor N_{\eta} t\right\rfloor+\mid \eta h\right\rfloor} \tilde{u}_{i}, 0 \leq t \leq 1-h \\
=w_{n}\left(\frac{\left\lfloor N_{\eta} t\right\rfloor+\lfloor\eta h\rfloor}{\eta}\right)-w_{n}\left(\frac{\left\lfloor N_{\eta} t\right\rfloor}{\eta}\right) \\
N_{\eta}=(\eta-\lfloor\eta h\rfloor) /(1-h)
\end{gathered}
$$

Table 2. Results of co-integration test

\begin{tabular}{ccrrrrr}
\hline $\begin{array}{c}\text { Null } \\
\text { Hypothesis }\end{array}$ & $\begin{array}{c}\text { Alternative } \\
\text { Hypotheis }\end{array}$ & Eigenvalues & $\begin{array}{c}\text { Trace } \\
\text { Statistics }\end{array}$ & $\begin{array}{c}\text { Critical } \\
\text { Value (\%5) }\end{array}$ & $\begin{array}{c}\text { Maximum } \\
\text { Eigenvalues }\end{array}$ & $\begin{array}{c}\text { Critical } \\
\text { Value (\%5) }\end{array}$ \\
\hline $\mathrm{r}=0$ & $\mathrm{r}=1$ & 0.38 & $101.09^{*}$ & 47.85 & $56.00^{*}$ & 27.58 \\
$\mathrm{r} \leq 1$ & $\mathrm{r}=2$ & 0.22 & $45.09^{*}$ & 29.79 & $29.65^{*}$ & 21.13 \\
$\mathrm{r} \leq 2$ & $\mathrm{r}=3$ & 0.12 & $15.43^{*}$ & 15.49 & $15.25^{*}$ & 14.26 \\
$\mathrm{r} \leq 3$ & $\mathrm{r}=4$ & 0.00 & 0.18 & 3.84 & 0.18 & 3.84 \\
\hline
\end{tabular}

In this study, MOSUM test was also applied using R package program. The results of both tests were shown in Figure 1. With respect to test results, the actual break was observed on 0.4 time period, because another structural break was observed in the model on later time periods, it may be suggested that the model had two structural breaks. As shown on Figure 1, MOSUM test gives more information than CUSUM test. Besides, when two structural breaks were observed 
in a model, more robust results were acquired from MOSUM test than the other tests (Chu et al., 1995).
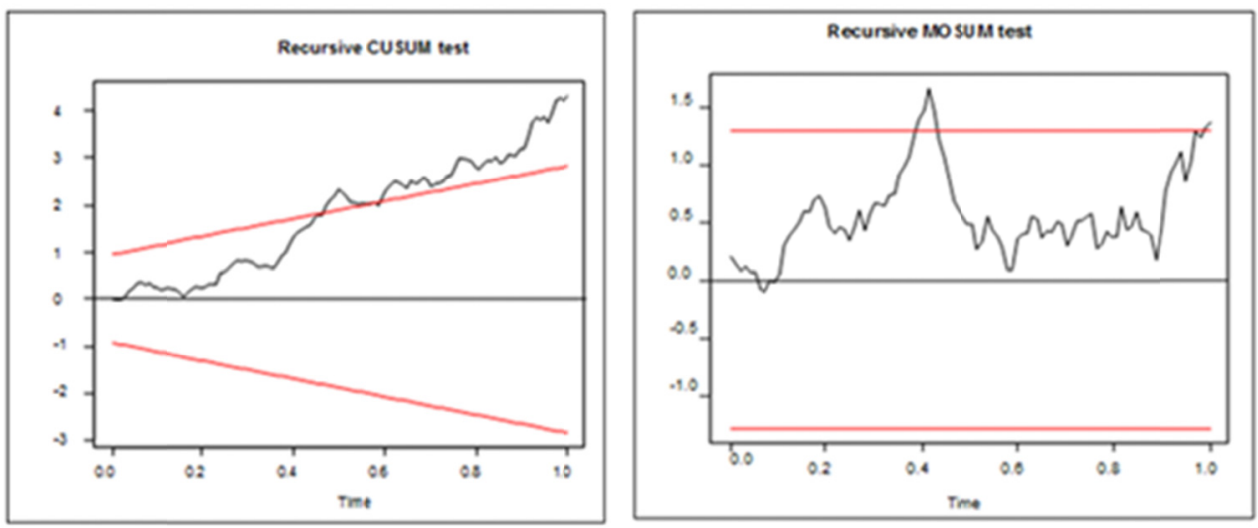

Figure 1. Recursive CUSUM and MOSUM test

\section{Conclusion and Discussion}

Econometrics and statistics employ to investigate techniques enabling the researchers to estimate the unknown parameters of a specific model. In that sense, model stability is an important requirement for convenient econometric estimation and interpretation. The common suggestion of the model stability researches emphasizes the neccessity of model stability against policy changes in order to use the model as an economy policy. Model stability can be tested by package programs with developing technology including CUSUM and CUSUMQ packages. In this study, model stability of money demand constituted by monthly time series concerning the periods 2001:5-2011:3 in Turkey was examined by structural break tests including recursive CUSUM and MOSUM tests. The study concentrated on the model stability tests that can be used when the policy change is slowly recognized in a time period at an unknown point. As the results of CUSUM and MOSUM tests, a single-continuous break and two discrete breaks were observed respectively. In this period, slow structural breaks in the model may be caused by the inflation targeting policies, restricted money supply and short-term interest policies of the government. In this period, estimated controlled money supply and short-term interest policies of government towards inflation objectives might lead to quiet structural breaks.

\section{References}

Akinlo, A. E. (2006). The stability of money demand in Nigeria: An autoregressive distributed lag approach. Journal of Policy Modelling, 28(4), 445-452. http://dx.doi.org/10.1016/j.jpolmod.2005.09.001

Andrews, D. W. K. (1993). Tests for parameter instability and structural change with unknown change point. Econometrica, 61(4), 821-856. http://dx.doi.org/10.2307/2951764

Andrews, D. W. K. (2003). End-of-sample instability tests. Econometrica, 71(6), 1661-1694. http://dx.doi.org/10.1111/1468-0262.00466

Andrews, D. W. K., \& Ploberger, W. (1994). Optimal tests when a nuisance parameter is present only under the alternative. Econometrica, 62(6), 1383-1414. http://dx.doi.org/10.2307/2951753

Bahmani-Oskooee, M. (2001). How stable is M2 money demand function in Japan?. Japan and the World Economy, 13(4), 455-461. http://dx.doi.org/10.1016/S0922-1425(01)00064-0

Bahmani-Oskooee, M., \& Bohl, M. T. (2000). German monetary unification and the stability of the German M3 money demand function. Economics Letters, 66(2), 203-208. http://dx.doi.org/10.1016/S0165-1765(99)00223-2

Bahmani-Oskooee, M., \& Chomsisengphet, S. (2002). Stability of M2 money demand function in industrial countries, Applied Economics, 34(16), 2075-2083. http://dx.doi.org/10.1080/00036840210128744

Bahmani-Oskooee, M., \& Economidou, C. (2005). How stable is the demand for money in Greece?. International Economic Journal, 19(3), 461-472. http://dx.doi.org/10.1080/10168730500199558

Bahmani-Oskooee, M., \& Rehman, H. (2005). Stability of the money demand function in Asian developing countries. Applied Economics, 37(7), 773-792. http://dx.doi.org/10.1080/0003684042000337424

Bahmani-Oskooee, M., \& Shin, S. (2002). Stability of the demand for money in Korea. International Economic Journal, 16(2), 85-95. http://dx.doi.org/10.1080/10168730200000015

Brown, R. L., Durbin, J., \& Evans, J. M. (1975). Techniques for testing the constancy of regression relationships 
over time. Journal of the Royal Statistical Society. Series B, 37(2), 149-192. http://dx.doi.org/10.2307/2984889

Chow, G. C. (1960). Tests of equality between sets of coefficients in two linear regressions. Econometrica, 28(3), 591-605. Retrieved from http://www.aae.wisc.edu/aae637/handouts/chow_test_article.pdf

Chou, W. L. (2007). Performance of the LM-type unit root tests with trend break: A bootstrap approach. Economics Letters, 94(1), 76-82. http://dx.doi.org/10.1016/j.econlet.2006.08.004

Chu, C. S. J., Hornik, K., \& Kaun, C. M. (1995). MOSUM tests for parameter constancy. Biometrika, 82(3), 603-617. http://dx.doi.org/10.1093/biomet/82.3.603

Clark, T. E., \& McCracken, M. W. (2005). The power of tests of predictive ability in the presence of structural breaks. Journal of Econometrics, 124(1), 1-31. http://dx.doi.org/10.1016/j.jeconom.2003.12.011

Enders, W. (1995). Applied econometric time series. New York: John Wiley \& Sons Inc.

Gagliardini, P., Trojani, F., \& Urga, G. (2005). Robust GMM tests for structural breaks. Journal of Econometrics, 129(1-2), 139-182. http://dx.doi.org/10.1016/j.jeconom.2004.09.006

Greene, W. G. (2002). Econometric analysis. New Jersey: Prentice Hall.

Gujarati, D. N. (1999). Basic econometrics. New Jersey: The McGraw-Hill Companies.

Hall, A. R., \& Sen, A. (1999). Structural stability testing in models estimated by Generalized Method of Moments. Journal of Business \& Economic Statistics, 17(3), 335-348. http://dx.doi.org/10.1080/07350015.1999.10524822

Hansen, B. E. (1992). Testing for parameter instability in linear Models. Journal of Policy Modeling, 14(4), 517-533. http://dx.doi.org/10.1016/0161-8938(92)90019-9

Harris, D., \& Mátyás, L. (1999). Introduction to the Generalized Method of Moments Estimation. In László Matyas (Ed.), Generalized Method of Moments Estimation (pp. 3-30). Cambridge: Cambridge University Press.

Hjort, N. L., \& Koning, A. (2002). Tests for constancy of model parameters over time. Nonparametric Statistics, 14(1-2), 113-132. http://dx.doi.org/10.1080/10485250211394

Johansen, S., \& Juselius, K. (1990). Maximum likelihood estimation and inference on cointegration with application to the demand for money. Oxford Bulletin of Economics and Statistics, 52(2), 169-210. http://dx.doi.org/10.1111/j.1468-0084.1990.mp52002003.x

Jondeau, E., Le Bihan, H., \& Gallès, C. (2004). Assessing Generalized Method-of-Moments estimator of the Federal Reserve reaction function. Journal of Business \& Economic Statistics, 22(2), 225-239. http://dx.doi.org/10.1198/073500104000000118

Khedhiri, S. (2006). Alternative tests for parameter stability. Communications in Statistics - Simulation and Computation, 35(2), 347-360. http://dx.doi.org/10.1080/03610910600591479

King, A., \& Ramlogan-Dobson, C. (2011). Nonlinear time-series convergence: The role of structural breaks. Economics Letters, 110(3), 238-240. http://dx.doi.org/10.1016/j.econlet.2010.12.001

Lee, J., Huang, C. J., \& Shin, Y. (1997). On stationary tests in the presence of structural breaks. Economics Letters, 55(2), 165-172. http://dx.doi.org/10.1016/S0165-1765(97)00073-6

Li, H., \& Müller, U. K. (2009). Valid inference in partially unstable Generalized Method of Moments models. Review of Economic Studies, 76(1), 343-365. http://dx.doi.org/10.1111/j.1467-937X.2008.00516.x

Lucas, R. E. (1981). Econometric policy evaluation: A critique. In Robert E. Lucas Jr. (Ed.), Studies in Business-Cycle Theory (pp. 104-130). Massachusetts: MIT Press.

Luger, R. (2001). A modified CUSUM test for orthogonal structural changes. Economics Letters, 73(3), 301-306. http://dx.doi.org/10.1016/S0165-1765(01)00497-9

Maheu, J. M., Gordon, S. (2008). Learning, forecasting and structural breaks. Journal of Applied Econometrics, 23(5), 553-583. http://dx.doi.org/10.1002/jae.1018

Nyblom, J. (1989). Testing for the constancy of parameters over time. Journal of the American Statistical Association, 84(405), 223-230. http://dx.doi.org/10.1080/01621459.1989.10478759

Oomes, N., \& Ohnsorge, F. (2005). Money demand and inflation in dollarized Economies: The case of Russia. Journal of Comparative Economics, 33(3), 462-483. http://dx.doi.org/10.1016/j.jce.2005.05.007

Ploberger, W., \& Krämer, W. (1992). The CUSUM test with OLS residuals. Econometrica, 60(2), 271-285. 
Retrieved from http://www.jstor.org/stable/2951597

Presno, M. J., \& López, A. J. (2003). Response surface estimates of stationary tests with a structural break. Economics Letters, 78(3), 395-399. http://dx.doi.org/10.1016/S0165-1765(02)00260-4

Quandt, R. E. (1960). Tests of hypothesis that a linear regression system obeys two separate regimes. Journal of American Statistical Association, 55(290), 324-330. doi: 10.1080/01621459.1960.10482067

Turner, P. (2010). Power properties of the CUSUM and CUSUMSQ tests for parameter instability. Applied Economics Letters, 17(11), 1049-1053. http://dx.doi.org/10.1080/00036840902817474

Yashchin, E. (1993). Performance of CUSUM control schemes for serially correlated observations. Technometrics, 35(1), 37-52. http://dx.doi.org/10.1080/00401706.1993.10484992

Zeileis, A. (2005). A unified approach to structural change tests based on ML Scores, F Statistics, and OLS Residuals. Econometric Reviews, 24(4), 445-466. http://dx.doi.org/10.1080/07474930500406053

Zeileis, A., \& Hornik, K. (2007). Generalized M-fluctuation tests for parameter instability. Statistica Neerlandica, 61(4), 488-508. http://dx.doi.org/10.1111/j.1467-9574.2007.00371.x

Zeileis, A., Hothorn, T., \& Hornik, K. (2008). Model-based recursive partitioning. Journal of Computational and Graphical Statistics, 17(2), 492-514. http://dx.doi.org/10.1198/106186008X319331

Zeileis, A., Leisch, F., Hornik, K., \& Kleiber, C. (2002). Strucchange: An R package for testing for structural change in linear regression models. Journal of Statistical Software, 7(2), 1-38. Retrieved from http://www.jstatsoft.org/v07/i02/paper 